\title{
RETROCESSOS NO SISTEMA DE COMUNICAÇÃO DE RISCOS NA ROTULAGEM DE AGROTÓXICOS: A CLASSIFICAÇÃO DA ANVISA
}

\author{
Érica Valente Lopes ${ }^{1}$ \\ Norma Suelí Padilha ${ }^{2}$
}

\section{RESUMO}

O presente artigo objetiva analisar a reclassificação toxicológica na rotulagem de produtos agrotóxicos no Brasil, conforme determinação da ANVISA (2019), contextualizando a atualidade do tema com o principio da Informação e parâmetros concedidos pelo Acordo de Escazú, Convenção de Aarhus e os Objetivos do Desenvolvimento Sustentável (ODS), da Agenda 2030 das Nações Unidas, referentes a saúde, bem estar, consumo e produção sustentável. A metodologia envolve pesquisa documental e bibliográfica interdisciplinar, a congregar qualitativamente teoria e práxis na articulação do Direito Ambiental e da Economia.

Palavras-chave: Rotulagem de agrotóxicos; Direito à informação; Comunicação de riscos, Acordo Escazú; Objetivos do Desenvolvimento Sustentável.

\section{RETROCESSES IN THE RISK COMMUNICATION SYSTEM IN AGROTOXIC LABELING: ANVISA'S CLASSIFICATION}

\begin{abstract}
This article aims to analyze the toxicological reclassification in the labeling of pesticides in Brazil, as determined by ANVISA (2019), contextualizing the current theme with the Information principle and parameters granted by the Escazú Agreement, Aarhus Convention and the Development Goals. Sustainable Development (SDG) of the United Nations Agenda 2030 concerning sustainable health, well-being, consumption and production. The methodology involves interdisciplinary documentary and bibliographical research, qualitatively bringing together theory and praxis in the articulation of Environmental Law and Economics.
\end{abstract}

Key-words: Pesticide labeling; Right to information; Risk Communication, Escazú Agreement; Sustainable Development Goals.

\section{INTRODUÇÃO}

\footnotetext{
${ }^{1}$ Advogada. Especialista em Direito Público. Mestranda em Direito Constitucional na Universidade de Fortaleza - UNIFOR. Pesquisadora do Grupo de Pesquisa CNPQ Relações Econômicas, Políticas, Jurídicas e Ambientais na América Latina - REPJAAL sob a orientação da Dra. Norma Suelí Padilha. Lattes: http://lattes.cnpq.br/5242391048637150 ORCID: http://orcid.org/0000-0002-3674-1957

E-mail: valente.erica@gmail.com

${ }^{2}$ Docente Permanente do Programa de Pós Graduação Stricto Sensu em Direito, Doutorado e Mestrado, da Universidade Federal de Santa Catarina - UFSC e Docente Colaboradora do Programa de Pós Graduação Stricto Sensu em Direito, Doutorado e Mestrado, da Universidade de Fortaleza - UNIFOR. Lattes: http://lattes.cnpq.br/7757445128600174 ORCID: http://orcid.org/0000-0001-7088-3767
} 
No presente artigo, analisa-se a recente modificação na rotulagem dos agrotóxicos quanto as informações sobre toxicidade do produto, conforme determinação da ANVISA, dimensionando os possíveis impactos na saúde humana sob o viés do direito à informação e da comunicação dos riscos, principalmente por se tratar de produtos químicos com níveis diversos de toxicidade. A reclassificação toxicológica, decidida pela Agência Nacional de Vigilância Sanitária (Anvisa) e divulgada, em 23 de Julho de 2019, institui um novo marco delimitatório para a rotulagem de agroquímicos. O temática impõe o debate sobre as falhas na comunicação de riscos sobre agrotóxicos, bem como do déficit de participação de diferentes atores sociais, e do efetivo cumprimento as medidas de prevenção determinadas pelos estudos científicos, refletindo em uma evidência de retrocessos nas medidas de prevenção e controle com relação aos riscos de contaminação humana e ambiental por agrotóxicos.

Adentra-se no tema conceituando e classificando os agrotóxicos, destacando-se as características de toxicidade inerentes ao produto, e percorrendo um breve histórico da política econômica que incrementou a denominada "Revolução Verde" incrementando o mercado agrário brasileiro e estimulando o uso de pesticidas para crescimento da produção alimentícia. Neste contexto, relacionam-se dados econômicos, isenções tributárias e a posição do Brasil no ranking de importador de agrotóxicos desde 2008.

A comercialização de agrotóxicos está diretamente correlacionada aos riscos ce contaminação ambiental e humana, em decorrência do uso abusivo, inadequado e excessivo de produtos, que mesmo que autorizados, não identificam segurança sem um rígido controle do sistema de controle de riscos, sob a responsabilidade estatal. A saúde ambiental e humana são bens indisponíveis e a prevenção exige uma extrema rigidez do sistema de controle de informações ao usuários e ao consumidor.

Neste contexto, o artigo apresente as recentes alteraçãos determinadas pela recategorização toxicológica nos rótulos de agrotóxicos pela Anvisa (2019), questionando os efeitos na comunicação de riscos aos usuáriros e consumidores do produto, e o aparente retrocesso provocado por esta mudança classificatória no direito a informação, clara, transparente e efetiva para evitar danos a saude socioambiental.

Destaca-se a atualidade e importância da pesquisa pontuando-se falhas na comunicação dos riscos, com suporte na seara internacional, destacada pelo Acordo de Escazú e pela Convenção de Aarhus, além dos Objetivos 03, 12, 14, 15 para o Desenvolvimento Sustentável (ODS), contidos na Agenda 2030 das Nações Unidas, respectivamente: saúde e 
bem estar, consumo e produção responsáveis, vida na água, vida terrestre.

A metodologia envolve pesquisa interdisciplinar com orientação epistemológica na teoria crítica, a congregar teoria e práxis na articulação do Direito Ambiental e da Economia. O texto adota raciocínios indutivo e dedutivo, em pesquisa qualitativa, com as técnicas de análise documental, estatísticas e de revisão bibliográfica.

\section{O FOMENTO DOS AGROTÓXICOS NA ECONOMIA AGRÍCOLA}

Toda a temática que envolve o controle de riscos de constaminação pelo uso de agrotóxicos perpassa a questão primordial da saúde socioambiental, e seu regramento estatal deve privilegiar sempre a prevenção na garantia do direito o direito de informação do usuário e do consumidor, uma vez que reflete diretamente na saúde coletiva e na preservação da qualidade ambiental.

Os produtos definidos como agrotóxicos são constituidos por uma vasta variedade de compostos químicos ou biológicos e são desenvolvidos primordialmente para matar, exterminar e combater a vida. Neste contexto, é que a normativa (Lei n 7.802 de 11 de Julho de 1989) conhecida como Lei do Agrotóxico, dispõe sobre a pesquisa, a experimentação, a produção, a embalagem e rotulagem, o transporte, o armazenamento, a comercialização, a propaganda comercial, a utilização, a importação, a exportação, o destino final dos resíduos e embalagens, o registro, a classificação, o controle, a inspeção e a fiscalização de agrotóxicos, conceitua os agrotóxicos em seu artigo $2^{\circ}$, I, da seguinte forma:

Art. $2^{\circ}$ Para os efeitos desta Lei, consideram-se:

I - agrotóxicos e afins:

a) os produtos e os agentes de processos físicos, químicos ou biológicos, destinados ao uso nos setores de produção, no armazenamento e beneficiamento de produtos agrícolas, nas pastagens, na proteção de florestas, nativas ou implantadas, e de outros ecossistemas e também de ambientes urbanos, hídricos e industriais, cuja finalidade seja alterar a composição da flora ou da fauna, a fim de preservá-las da ação danosa de seres vivos considerados nocivos; [...]

Nota-se que a legislação brasileira reconheceu a periculosidade inata ao produto quando optou pela nomenclatura agrotóxico, ao invés de outras denominações circulantes, como: agentes fitossanitários, defensivos agrícolas. Rubens Nodari (2012, p. 112) enfatiza a insistência com que políticos, universidades e técnicos governamentais, estadual e municipal utilizam expressões mais amenas para referirirem-se a um produto ao qual se exige cautela e precaução no manuseio.

Revista de Direito Ambiental e Socioambientalismo | e-ISSN: 2525-9628 | Belém | v. 5 | n. 2 |

p. 55 - 76 | Jul/Dez. 2019. 
A identificação de agrotóxicos com uma nomenclatura mais amena não é proposta isenta de interesses comerciais, pois o processo de crescimento na comercialização esta diretamente atrelada ao markenting do produto e sua oferta no mercado de forma mais palatável a sociedade, para que haja uma aceitação implicita da produção agricola incrementada pelo uso de pesticidas. Mascara-se, a primeira vista, desde a embalagem, a imagem primária de toxicidade e periculosidade que tais produtos contém, sendo uma forma de ocultar os riscos, num mecanismo de irresponsabilidade organizada. (BECK, 2016, p. 55).

\subsection{Crescimento na Comercialização Mundial e no Brasil}

A partir de 1950, a comercialização de agrotóxicos iniciou um processo de crescimento vertiginoso por conta da fácil aplicação, fomento do Estado e maior eficácia de caráter econômico (AMARO, 2007, p. 39). Contrariamente aos ditames da sustentabilidade ecológica, a Revolução Verde, em meados da década de 60, fez com que houvesse a massificação da utilização dos pesticidas, pois consistiu na adoção massiva de práticas agrícolas baseadas no uso de insumos químicos e instrumentos mecânicos pelos países em desenvolvimento (ALBERGONI, 2007, p. 39).

Dessa forma, muitas nações em desenvolvimento passaram a utilizar agrotóxicos incluindo-se, assim, na denominada "Revolução Verde" que imbutia a proposta solidária de acabar com a fome no mundo. A partir da intensificação do uso de agrotóxicos obtinha-se maior produção em uma mesma extensão de território de plantio, com possibilidade de expansão para áreas antes não cultivadas. Abriu-se espaço para que empresas que investissem em estudos e produção de sementes de alta produtividade e produtos agroquímicos consolidassem-se no mercado. (VANDANA, 1997, p. 64).

A despeito do aumento da produtividade, os custos ambientais e sociais não foram devidamente considerados, uma vez que o uso de agrotóxicos sintéticos na natureza aumenta os índices de contaminação da terra, dos lençóis freáticos e animais, além do risco de intoxicação do ser humano manuseador, muitas vezes sem a capacitação suficiente para proteger-se do produto pulverizado (PORTO, 2008, p.146).

Não se pode olvidar que pequenos produtores permaneceram à margem desse processo de crescimento econômico, pois a modernização da agricultura foi exigida também pelos bancos financiadores que viam na utilização de agrotóxicos uma maior garantia de 
adimplemento dos empréstimos realizados por agricultores. (THRUPP, Lori Ann, 1990, p. 64). Nesta política de crédito, quem não utilizasse herbicidas não obteria investimento para a próxima lavoura.

As normatizações tributárias reforçam a política econômica que, desde o Decreto 7.660, de 23 de dezembro de 2011, permite a isenção total do imposto sobre produtos industrializados - IPI, e o Convênio ICMS n ${ }^{\circ}$ 100/97, do Conselho Nacional de Política Fazendária - CONFAZ, em sua cláusula primeira e terceira, estimula e reduz $60 \%$ da base de cálculo do Imposto sobre Circulação de Mercadorias e Prestação de Serviços - ICMS ${ }^{3}$.

Com base nesse estímulo político-normativo-financeiro, o Brasil tornou-se o maior importador de agrotóxico desde 2008, tendo superado, inclusive, os Estados Unidos, até então maiores produtores e defensores do produto. A utilização deste produto na agricultura brasileira movimenta US\$ 8,5 bilhões por ano, em sua maioria, lavouras de soja, milho, algodão e cana-de-açúcar, responsáveis por $80 \%$ do total das vendas do setor (ABRASCO, 2015, p. 49).

Apesar da intensa movimentação financeira, os Estados não absorvem o lucro do mercado rentável. Isso por que, conforme retro mencionado, isenções e reduções na base de cálculo tributátria dos agrotóxicos incentivam o comércio, porém, os ganhos permanecem em parcela ínfima de quem pratica o agronegócio, como se pode depreender dos dados expostos por Rute Pina (2019):

O cálculo é ainda maior se consideradas as isenções dadas pelos estados. Novaes investigou, no âmbito da Defensoria Pública, a perda tributária com as desonerações do ICMS em São Paulo. Em 2015, o estado deixou de arrecadar R \$ 1,2 bilhão com a comercialização, importação e transporte do insumo - valor menor do que o orçamento da Secretaria Estadual de Agricultura no mesmo ano, de R 1,12 bilhão.

Deste montante, R $\$ 400$ milhões foram fruto do Convênio $\mathrm{n}^{\circ}$ 100/97 do Conselho Nacional de Política Fazendária (Confaz), que permite redução da base de cálculo dos impostos e está sendo questionado no Supremo Tribunal Federal (STF). Em 2016, o Partido Socialismo e Liberdade (PSOL) ajuizou uma ação que questiona constitucionalidade das cláusulas.

De acordo com a Organização das Nações Unidas para a Alimentação e a Agricultura (FAO), a média de uso de agrotóxicos nos EUA é de 2,38 kg/ha e no Canadá é de 0,93 kg/ha.

\footnotetext{
${ }^{3}$ Cláusula primeira - Fica reduzida em $60 \%$ (sessenta por cento) a base de cálculo do ICMS nas saídas interestaduais dos seguintes produtos: I - inseticidas, fungicidas, formicidas, herbicidas, parasiticidas, germicidas, acaricidas, nematicidas, raticidas, desfolhantes, dessecantes, espalhantes, adesivos, estimuladores e inibidores de crescimento (reguladores), [...];

Cláusula terceira - Ficam os Estados e o Distrito Federal autorizados a conceder às operações internas com os produtos relacionados nas cláusulas anteriores, redução da base de cálculo ou isenção do ICMS, observadas as respectivas condições para fruição do benefício.
} 
A média brasileira $(2,77 \mathrm{~kg} / \mathrm{hs})$ é, portanto, maior que a de ambos. É conveniente também compararmos a condição brasileira com a de países da América Latina, grandes produtores agrícolas, com o é o caso da Argentina e do México, que têm dimensões territoriais consideráveis, de cerca de 2 milhões de $\mathrm{Km}^{2}$, e, também, com extensas monoculturas. A Argentina é um grande produtor agrícola e destaca-se, dentre outros, na produção de milho, soja e trigo. O México que, assim como a Argentina e o Brasil, também tem uma importante produção agrícola, destaca-se nos cultivos de milho, feijão, algodão e café. A média de consumo de agrotóxicos na Argentina é de $2,37 \mathrm{~kg} / \mathrm{ha}$ e a média mexicana é de $1,35 \mathrm{~kg} / \mathrm{ha}$. A média brasileira é, portanto, superior às médias de consumo de agrotóxicos de ambos os países latino-americanos (BOMBARDI, 2019).

Sabe-se que a escassez de alimentos não é o problema da fome no mundo, mas sim, a distribuição de forma não democrática (CAPRA, 2005, p. 197). Por mais que sejam apontadas melhorias na produção e economia exportadora agrícola, a principal consternação reside no dimensionamento dos danos ao meio ambiente, dos riscos à alimentação humana, no cumprimento do direito à informação e na proteção à integridade e saúde do consumidor, bases para a construção de uma vida saudável e digna.

\subsection{Perigos e riscos advindos do crescente uso de agrotóxicos}

Diante do aumento no manuseio de herbicidas na agricultura brasileira, questões passaram a ser levantadas quanto ao perigo de intoxicação do produtor rural, aos riscos à saúde humana pela ingestão de alimentos com resquícios do produto e à contaminação do meio ambiente. Em 2001, o Programa de Análise de Resíduos de Agrotóxicos (PARA) foi criado no objetivo de cumprir as normas dispostas na Lei $\mathrm{n}^{\mathbf{0}} 7.802 / 89$, no Decreto regulamentador $n^{\circ}$ 4.074/02 e na Resolução - RDC n 44/00.

Os objetivos específicos do PARA são (1) analisar resíduos de agrotóxicos in natura; (2) verificar se os alimentos contaminados ultrapassam o limite máximo de resíduo (LMR); (3) verificar a presença de resíduos de a grotóxicos não autorizados pela legislação em vigor; (4) rastrear possíveis problemas e subsidiar ações de fiscalização de vigilância sanitária; (5) melhorar a estimativa de exposição por meio da dieta, como parte da reavaliação dos agrotóxicos já registrados; (6) monitorar o uso de produtos agrotóxicos realizando um mapeamento de risco; (7) subsidiar com base científica e informações laboratoriais concretas 
as negociações internacionais, principalmente, no âmbito do Codex Alimentarius e do Mercosul; (8) fornecer subsídios ao Ministério da Agricultura que permitam orientar e fiscalizar os produtores na utilização dos agrotóxicos; e (9) disponibilizar informações à sociedade.

A Organização Mundial da Saúde (OMS) acredita que, anualmente, 3 a 5 milhões de pessoas são intoxicadas por agrotóxicos no mundo, a maioria por organofosforados $(70 \%)$. O trabalhador rural, muitas vezes por desinformação ou falta de recursos, não utiliza os equipamentos de proteção individual (EPI's) no momento da preparação e utilização do produto químico. Além disso, deve-se alertar que estes protetores não foram testados e aprovados em condições climáticas e laborais extensas brasileiras.

As principais vias de penetração no corpo do ser humano, em ordem crescente, são: por ingestão, pela respiração e por absorção dérmica. Dentre as complicações à saúde, apontase a intoxicação aguda, na qual os sintomas surgem algumas horas após a exposição excessiva, por curto período, a produtos altamente tóxicos, podendo ocasionar fraqueza, vômitos, náuseas, convulsões, contrações musculares, dores de cabeça, dificuldade respiratória, sangramento nasal, desmaio; e a crônica, que se caracteriza pelo surgimento tardio, em meses ou anos, por exposição pequena ou moderada a produtos tóxicos ou a múltiplos produtos, com casos relatados de dermatite de contato, lesões renais e hepáticas, efeitos neuroóxicos retardados, alterações cromossominais, doença de Parkinson, cânceres e teratogêneses (STOPPELLI, 2005, p. 91-96).

Os resíduos destes produtos nos alimentos são outra consternação, principalmente aos consumidores que carecem de informações. O Dossiê ABRASCO, fruto de um compilado de pesquisas realizadas por intermédio de órgãos oficiais, publicizou dados em torno da segurança alimentar, constatando que os alimentos absorvem agrotóxicos, alguns em maior quantidade que outros, podendo atravessar a casca e atingir o mesocarpo.

O PARA revelou, em 2011, que um terço dos alimentos cotidianos da alimentação brasileira estão contaminados pelos agrotóxicos. Utiliza-se na agricultura aproximadamente 500 mil toneladas de agrotóxicos, equivalendo a 7 litros de consumo por brasileiro ao ano. Desses alimentos, as culturas agrícolas que mais absorvem os herbicidas são: pimentão $(91,8 \%)$, morango $(63,4 \%)$, pepino $(57,4 \%)$, alface $(54,2 \%)$, cenoura $(49,6 \%)$, abacaxi $(32,8 \%)$, beterraba $(32,6 \%)$ e mamão $(30,4 \%)$. Ressalte-se que, mesmo lavando os alimentos, resquícios dos herbicidas ainda permanecem na casca dos alimentos, o que torna mais 
dificultoso o resguardo da segurança alimentar humana.

Em 2019, o Instituto Butantan divulgou pesquisa encomendada pelo Ministério da Saúde para analisar a toxicidade de dez agrotóxicos em peixes-zebra cujo genoma é $70 \%$ igual ao do ser humano. Foram utilizados herbicidas largamente utilizados na agricultura brasileira, a saber: abamectina, acefato, alfacipermetrina, bendiocarb, carbofurano, diazinon, etofenprox, glifosato, malathion e piripoxifem. $\mathrm{O}$ resultado foi alarmante, pois três dos dez pesticidas analisados (glifosato, melathion e piriproxifem) causaram a morte de todos os embriões de peixes em apenas 24 horas de exposição, independentemente da concentração do produto.

Os outros sete pesticidas analisados (abamectina, acefato, alfacipermetrina, bendiocarb, carbofurano, diazinon, etofenprox) causaram mortes de peixes em maior ou menor porcentagem, em todas as concentrações testadas. E mesmo entre os que sobreviveram apresentaram padrão de nado alterado por malformação das nadadeiras ou problemas neuromotores decorrentes da exposição ao veneno.

A imunologista Mônica Lopes-Ferreira, responsável pela pesquisa, complementa que os resultados são um alerta, pois não existem quantidades seguras, matam ou causam anomalias: "Essas substâncias podem causar sérios problemas aos trabalhadores que as manipulam e ao ecossistema como um todo". E complementa: "Conforme o agrotóxico é borrifado nas verduras e nas frutas, ele cai no solo, na água, contamina todos os animais que estão ali e também o homem que se alimenta desses animais e desses vegetais. É uma cadeia" (JANSEN, 2019).

O estudo em peixes revela uma grande chance em estar ocorrendo o mesmo com os seres humanos e a natureza, pois aqueles comportam-se como sentinelas indicando que algo além está ocorrendo. Problemática esta já trazida por Ulrich Beck (2016, p. 31) no livro “Sociedade do Risco" em que aborda os riscos invisíveis advindos da mercantilização das riquezas, vide:

Um problema especialmente grave é que investigações voltadas unicamente a substâncias tóxicas isoladas jamais podem dar conta das concentrações tóxicas no ser humano. Aquilo que parece ser "inofensivo" num produto isolado talvez seja consideravelmente grave no "reservatório do consumidor final", algo em que o ser humano acabou por se converter no estágio avançado da mercantilização total. Trata-se, nesse caso, de uma falácia categorial: uma análise de toxicidade que tome por base a natureza de forma geral ou produtos isolados não têm condições de

Revista de Direito Ambiental e Socioambientalismo | e-ISSN: 2525-9628 | Belém | v. 5 | n. 2 |

p. 55 - 76 | Jul/Dez. 2019.

62 
responder à questão inocuidade, de todo modo não enquanto "gravidade" ou "inocuidade" tiverem algo a ver com as pessoas ingerem ou aspiram a substância (ver com mais detalhe pp. 77 ss.). [...] Tornam-se elas desse modo - como é o caso comum das adições de acordo com as regras da matemática - sempre mais inócuas?

Soma-se a isso, a frágil estrutura de controle e vigilância dos órgãos de fiscalização frente ao grande número de agrotóxicos liberados ao uso em 2019, totalizando 290 até o mês de Julho. O resultado da pesquisa concluída em Agosto de 2019, portanto, após divulgação do novo marco delmitatório, foi entregue ao Ministério da Saúde e à Anvisa, os quais ainda não se pronunciaram oficialmente. Nesse sentido, a extensão dos danos é frequentemente alertada por estudiosos (FRANCO, DRUCK, 1998, p.65-66):

Nesse caminho há expansão progressiva do alcance dos riscos, isto é, do seu raio de ação; o local e o global se interconectam e a potencialidade de degradações socioambientais ultrapassa os locais de ocorrência de acidentes/contaminações, não se limitando, portanto, às localidades ou às fronteiras geopolíticas dos países de origem. As chuvas ácidas e as alterações do efeito estufa são claros exemplos. Além do alcance ampliado, há intensa mobilidade dos riscos, "seja por meio de dutovias e diversos meios de transportes e armazenamento de produtos, seja por meio das emissões previstas das plantas e/ou fugitivas, são muitas as formas de disseminação de efluentes líquidos, sólidos e gasosos. Por meio desta mobilidade, vastas extensões de terras, ar e águas são percorridas e integradas como áreas de impactos sócioambientais e de riscos em todo o planeta".

Infelizmente, como exposto, o Brasil ainda possui políticas públicas a fomentar o uso e comércio de agrotóxicos, como o baixo custo do registro de produtos na Anvisa e na isenção de IPI (imposto sobre pordutos importados), além de benefícios em grande parte dos estados federados, a exemplo do ICMS (imposto estadual sobre a comercialização). Tal contexto produz resultados como os da última década, na expansão do Brasil em 190\% no mercado de agrotóxicos, o que colocou o País em primeiro lugar no ranking mundial de consumo, desde 2008, em detrimento do princípio da precaução, prevenção e da comunicação dos riscos.

\section{MARCO LEGAL PARA A CLASSIFICAÇÃO E ROTULAGEM DE AGROTÓXICOS DA ANVISA DE 2019}

Em razão da periculosidade inerente ao produto, instrumentos legais sobre registro, uso, manuseio, descarte dos agrotóxicos são indispensáveis, pois a segurança quanto aos riscos depende da qualidade do sistema, que deve garantir uma estrutura de controle e vigilância, principalmente diante da grande quantidade de produtos liberados para comérico 
no território brasileiro. No que se refere a questão do registro de agrotóxicos, por exemplo, deve-se regular todo oo procedimento de análise da substância nociva a ser inserida na agricultura nacional, por meio de atuação eficiente dos órgãos competentes.

Com a cautela que requer a questão, o registro de agrotóxicos no país é complexo, a envolver três órgãos federais distintos e ligados ao Poder Executivo. O Ministério da Agricultura, Pecuária e Abastecimento (Mapa), responsável por avaliar a eficiência e o potencial de uso na agricultura, por meio de um dossiê agronômico. O Instituto Brasileiro do Meio Ambiente e dos Recursos Naturais Renováveis (Ibama), autarquia federal ligada ao Ministério do Meio Ambiente, o qual realiza um dossiê ambiental, no qual é avaliado o potencial poluidor do produto. E, por último, Agência Nacional de Vigilância Sanitária (Anvisa), agência reguladora vinculada ao Ministério da Saúde, que produz um dossiê toxicológico a avaliar quão tóxico o produto é para a população e em quais condições o seu uso é seguro.

Em razão da toxicidade do produto, medidas preventivas devem perpassar todo o procedimento de registro do produto. Por esse motivo, antes que o Ministério da Agricultura conclua o procedimento, o Ibama e a Anvisa devem oportunizar estudos técnicos para embasar a decisão de liberação do produto. Por outro lado, deve-se considerar os inúmeros direitos envolvidos, entre os quais: o direito à saúde, bem estar, a segurança alimentar, o direito à informação, a proteção do meio ambiente, que devem ser ponderados frente ao livre exercício da liberdade econômica.

A partir do momento em que uma substância é classificada como agrotóxico, o manuseio de quantidade superior a 25 (vinte e cinco) gramas exige-se procedimento específico, de acordo com a lei. O pleito inicial deve ser protocolado em cada um dos órgãos federais mencionados, acompanhado dos respectivos relatórios, dados e informações exigidos em normas complementares específicas, visando a avaliação técnico-científica, fins de registro ou reavaliação de registro no prazo de até cento e vinte dias, contados a partir da data do respectivo protocolo. A contagem do prazo é suspensa caso qualquer dos órgãos avaliadores solicite fundamentadamente por escrito, informações adicionais, reiniciando o prazo a partir do atendimento da exigência, acrescidos trinta dias, artigo 15 do Decreto $\mathrm{n}^{\circ}$ 
$4.074 / 02^{4}$.

Conforme aduz o artigo $20^{5}$ do referido decreto, o registro de novo produto agrotóxico, componentes e afins somente será concedido se a sua ação tóxica sobre o ser humano e o meio ambiente for, comprovadamente, igual ou menor a daqueles já registrados para o mesmo fim. É avaliada tecnicamente a toxicidade, a bioacumulação, a toxicologia neural, hormonal, comportamental e reprodutiva, e ainda, a forma de apresentação e o método de aplicação.

Quanto à toxicidade, tece-se especial atenção, pois de acordo com a Embrapa (Empresa Brasileira de Pesquisa Agropecuária), esta é definida pela Dose Média Letal (DL50), que se refere ao número de miligramas do ingrediente ativo do agrotóxico necessários para matar 50\% (cinquenta por cento) dos animais em um teste de laboratório (BRASIL, 2019).

O regramento normativo vigente impõe, em certa medida, a imprescindibilidade da prevenção por meio de estudos técnicos, a serem devidamente considerados e respeitados e considerados para a aprovação e registro de novo agrotóxico a ser inserido no meio ambiente e, consequentemente, na alimentação dos seres humanos.

\footnotetext{
${ }^{4}$ Art. 15 Decreto $\mathrm{n}^{\circ}$ 4.074/02 Os órgãos federais competentes deverão realizar a avaliação técnico-científica, para fins de registro ou reavaliação de registro, no prazo de até cento e vinte dias, contados a partir da data do respectivo protocolo.

$\S 1^{-}$A contagem do prazo será suspensa caso qualquer dos órgãos avaliadores solicite por escrito e fundamentadamente, documentos ou informações adicionais, reiniciando a partir do atendimento da exigência, acrescidos trinta dias.

$\S 2^{\mathrm{O}}$ A falta de atendimento a pedidos complementares no prazo de trinta dias implicará o arquivamento do processo e indeferimento do pleito pelo órgão encarregado do registro, salvo se apresentada, formalmente, justificativa técnica considerada procedente pelo órgão solicitante, que poderá conceder prazo adicional, seguido, obrigatoriamente, de comunicação aos demais órgãos para as providências cabíveis.

$\S 3^{-}$Quando qualquer órgão estabelecer restrição ao pleito do registrante deverá comunicar aos demais órgãos federais envolvidos.

$\S 4^{\circ} \mathrm{O}$ órgão federal encarregado do registro disporá de até trinta dias, contados da disponibilização dos resultados das avaliações dos órgãos federais envolvidos, para conceder ou indeferir a solicitação do requerente.

${ }^{5}$ Art. 20 Decreto $\mathrm{n}^{\circ}$ 4.074/02 O registro de novo produto agrotóxico, seus componentes e afins somente será concedido se a sua ação tóxica sobre o ser humano e o meio ambiente for, comprovadamente, igual ou menor do que a daqueles já registrados para o mesmo fim.

Parágrafo único. Os critérios de avaliação serão estabelecidos em instruções normativas complementares dos órgãos competentes, considerando prioritariamente os seguintes parâmetros:

I - toxicidade;

II - presença de problemas toxicológicos especiais, tais como: neurotoxicidade, fetotoxicidade, ação hormonal e comportamental e ação reprodutiva;

III - persistência no ambiente;

IV - bioacumulação;

$\mathrm{V}$ - forma de apresentação; e

VI - método de aplicação.
}

Revista de Direito Ambiental e Socioambientalismo | e-ISSN: 2525-9628 | Belém | v. 5 | n. 2 |

p. 55 - 76 | Jul/Dez. 2019. 


\subsection{Novo Marco Regulatório dos Agrotóxicos (ANVISA, 2019)}

O rótulo é a identidade do produto, com informações detalhadas e esclarecedoras sobre os componentes em seu invólucro, a fim de que o consumidor possa exercer sua escolha. Além da lista de ingredientes, o rótulo deve indicar quantidade, prazo de validade, informação nutricional, número do Serviço de Inspeção Federal (SIF), forma de manuseio, toxicidade e alertas de perigo à saúde, dentre outros dados. A Portaria $n^{\circ} 2.658 / 2003$, dispõe que rotulagem "é toda inscrição, legenda, imagem ou toda matéria descritiva ou gráfica que seja escrita, impressa, estampada, gravada, gravada em relevo ou litografada ou colada sobre a embalagem." (BRASIL, 2003).

A ANVISA, o órgão responsável por avaliar e classificar a toxicidade dos produtos expostos à comercialização aprovou em data recente ( 23 de Julho de 2019), por intermédio de sua diretoria colegiada, novo marco regulatório para agrotóxicos a fim de adequar-se aos padrões do Sistema Globalmente Harmonizado de Classificação e Rotulagem de Produtos Químicos (Globally Harmonized System of Classification and Labelling of Chemicals - GHS), o qual foi lançado em 1992, durante a ECO 92, e no Brasil, endossada pela Assembleia Geral da Organização das Nações Unidas (ONU), no sentido de fortalecer os esforços internacionais relativos à gestão ambientalmente segura de produtos químicos. (MAPA, 2019).

Objetivou-se harmonizar as regras do Brasil as de países da União Europeia e Ásia, entre outros, no fito de fortalecer a comercialização de produtos nacionais no exterior. Existem 53 países adotantes dos padrões do GHS e 12 com implementação parcial, como antes o Brasil, a Austrália e o México, de acordo com dados de 2017, do Instituto do Meio Ambiente de Estocolmo (Stockholm Environment Institute - SEI).

Com a medida, venenos antes considerados "altamente tóxicos" que provocam irritação severa na pele, passam para toxicidade moderada, enquanto os "pouco tóxicos", com risco de irritação leve na pele e nos olhos, ficam liberados de classificação, ou seja, não apresentarão advertências no rótulo para o consumidor. Já os que pertencem ao patamar de “extremamente tóxicos", hoje com 800 tipos, podem cair para 300. 
Segundo a Anvisa, as novas regras atualizam e tornam mais claros os critérios de avaliação e de classificação toxicológica dos produtos no Brasil, trazendo mais segurança para o mercado consumidor porque facilitam a identificação do perigo de uso. Outras mudanças na rotulagem são a adoção do uso de informações, palavras de alerta e imagens (pictogramas) que facilitam a identificação de perigos à vida e à saúde humana. O novo marco regulatório é composto por Resoluções da Diretoria Colegiada (RDCs) e uma Instrução Normativa (IN), todas do órgão sanitarista. Antes da avaliação, as propostas foram submetidas a Consultas Públicas (CPs), em 2018.

Esclarece o órgão que o GHS define a classificação para fins de rotulagem do produto de acordo com o desfecho de morte, analisado nos estudos toxicológicos agudos. Para isso, ampliou-se, de quatro para cinco, as categorias da classificação toxicológica, além da inclusão do item "não classificado", válido para produtos de baixíssimo potencial de dano, como os produtos de origem biológica.

Apesar do discurso amparado em normativas internacionais, especialistas, como o engenheiro agrônomo Leonardo Melgarejo, da Campanha Permanente contra os Agrotóxicos e pela Vida, discorda de que esta alteraçao seja um avanço, pois a nova metodologia impõe riscos à saúde humana porque os pesticidas têm reconhecida ligação a diferentes tipos de males. Além de sobrevalorizar a classificação com base no evento morte, olvidando preocupações de longo prazo, como câncer, cegueira, problemas de raciocínio e no sistema nervoso central, sendo, na verdade, uma forma de enganar a sociedade, pois poderá minimizar o cuidado das pessoas com o manuseio dos agrotóxicos que não causam a morte, mas que trazem dramas que, para uma família, são tão relevantes quanto a perda de um parente. (SAMPAIO, 2019). Acrescenta ainda o especialista, que mais de $30 \%$ dos venenos que circulam nacionalmente são rejeitados pelos países referenciados como exemplo:

Seria racional que nós tivéssemos um modelo semelhante, mas, na comunidade
econômica europeia, pelo que sabemos, são proibidos vários dos produtos que são
autorizados aqui. Seria de se esperar que uma reclassificação que compatibilizasse a
realidade brasileira com a europeia retirasse do mercado esses produtos. No entanto,
não há nenhuma sinalização nesse sentido.

A retirada do pictograma da caveira, antes disposta em todos os invólucros, também não agradou alguns especialistas. Isso porque ela somente será usada para as duas categorias consideradas mais perigosas. Com isso, produtos considerados "moderadamente tóxicos", "pouco tóxicos" ou "improváveis de causar dano agudo" não terão o símbolo no rótulo. A

Revista de Direito Ambiental e Socioambientalismo | e-ISSN: 2525-9628 | Belém | v. 5 | n. 2 |

p. 55 - 76 | Jul/Dez. 2019. 
coordenadora da campanha de Agricultura e Alimentação do Greenpeace, Marina Lacôrte, avalia que a mudança traz prejuízos para o entendimento do consumidor (SAMPAIO, 2019):

Isso acaba confundido muito a sociedade porque não existe agrotóxico que não apresente nenhum tipo de perigo. A caveira era totalmente didática e remetia ao risco crônico oferecido pelos produtos, que podem oferecer mais ou menos riscos, mas o perigo é algo intrínseco a essas substâncias. Ele sempre está ali, então, isso coloca, sim, a sociedade em maior risco.

Cumpre observar que não se sabe bem ao certo como ocorreram as audiências públicas, se devidamente divulgadas e ocorridas em local e hora de fácil acesso e com a participação da coletividade interessada. Contudo, por mais que a reclassificação implique em danos ambientais e retrocessos ao direito à informação, a nova classificação já está em pleno aplicação, tendo a Anvisa publicou edital de requerimento de informações que deve ser respondido pelos detentores de registro. E dos 2.300 agrotóxicos registrados no Brasil, já foram recebidos dados para reclassificação de aproximadamente 1.950 (85\%) produtos.

\subsection{Retrocessos na Comunicação de Riscos}

Muito embora a Lei dos Agrotóxicos regulamente a rotulagem dos produtos classificados como agrotóxicos, tais determinações já não se mostram suficientes para fazer cumprir a dimensão necessária de comunicação de risco. Neste ponto, Paulo Affonso da Silva (2018, p. 203) pontua: "que o regulamento foi incompleto em não obrigar que outros dados devessem constar da publicação, tais como a classificação referente à toxicidade humana e os resultados dos testes efetuados assim como das análises indicativas da persistência de resíduos". 6

Mencione-se que, em qualquer produto que se comercialize, se a publicidade não segue o parâmetro da transparência há a possibilidade de o consumidor adquirir um produto não adequado ao que ele pretende, podendo ocasionar danos à sua saúde, por não corresponder a sua legítima expectativa por insuficiência ou omissão da informação. Em

\footnotetext{
${ }^{6}$ Art. $8^{\circ}$, Lei $\mathrm{n}^{\mathrm{o}} 7.802 / 89$ A propaganda comercial de agrotóxicos, componentes e afins, em qualquer meio de comunicação, conterá, obrigatoriamente, clara advertência sobre os riscos do produto à saúde dos homens, animais e ao meio ambiente, e observará o seguinte:

I - estimulará os compradores e usuários a ler atentamente o rótulo e, se for o caso, o folheto, ou a pedir que alguém os leia para eles, se não souberem ler;

II - não conterá nenhuma representação visual de práticas potencialmente perigosas, tais como a manipulação ou aplicação sem equipamento protetor, o uso em proximidade de alimentos ou em presença de crianças;

III - obedecerá ao disposto no inciso II do $\S 2^{\circ}$ do art. $7^{\circ}$ desta Lei.
} 
regra, os produtos e serviços expostos a consumo não acarretam riscos à saúde do consumidor. Caso haja potencialidade de nocividade num produto, ou seja, perigoso por sua natureza, as informações devem ser expostas em seus rótulos de forma clara, correta e precisa $^{7}$, visando proteger a saúde e segurança do consumidor, conforme normatizado nos artigos $8^{\circ}$ e $9^{\circ}$ do $\mathrm{CDC}^{8}$, patamar em que se inserem os agrotóxicos.

Nessa seara, em que o produto exposto à venda possui toxicidade, imprescindível se mostra a comunicação dos riscos sobre a utilização e reações adversas no manuseio. Mensagem esta que possui, nos rótulos dos alimentos, o instrumento de alcance mais próximo e efetivo ao receptor/consumidor, momento em que este exerce o poder de convencimento e livre arbítrio em adquirir ou não a mercadoria. A construção da confiança é vista de modo vinculado à percepção de precisão, conhecimento e preocupação com o bem-estar público. Maria Lígia Rangel (2007, p. 1.376-1.377), corrobora:

...a comunicação do risco, que é entendida como o intercâmbio interativo de informações e opiniões sobre os riscos entre as pessoas encarregadas da avaliação dos riscos e do gerenciamento dos riscos, os consumidores e outras partes interessadas. O risco tem sido objeto de estudos diversos, desde a década de 60 , nas abordagens quantitativas, e desde 80 , nas qualitativas, nos mais varia dos campos de conhecimento. Estudos recentes em torno do risco reconhecem as significativas contribuições de Beck e Giddens, como principais autores/leitores do risco na sociedade contemporânea a partir da década de 80.

Contudo, principalmente quando insertos em países em desenvolvimento, em que a voz, o conhecimento e a educação ainda são precárias por uma herança cultural de negligência em políticas públicas, vislumbram-se verdadeiras sociedades de risco, denominação trazida por Ulrich Beck (2016, p.23), a partir de estudos relacionados às sociedades da escassez, dotadas de problemas e conflitos distributivos, nas quais a produção social de riqueza é acompanhada sistematicamente pela produção social de riscos. Prossegue o autor conceituando o risco como um modo sistemático de lidar com o perigo e incertezas induzido e introduzido pela modernização em si. Risco, em oposição aos velhos perigos, são

\footnotetext{
${ }^{7}$ Art. 31 CDC A oferta e apresentação de produtos ou serviços devem assegurar informações corretas, claras, precisas, ostensivas e em língua portuguesa sobre suas características, qualidades, quantidade, composição, preço, garantia, prazos de validade e origem, entre outros dados, bem como sobre os riscos que apresentam à saúde e segurança dos consumidores.

${ }^{8}$ Art. $8^{\circ}$ CDC Os produtos e serviços colocados no mercado de consumo não acarretarão riscos à saúde ou segurança dos consumidores, exceto os considerados normais e previsíveis em decorrência de sua natureza e fruição, obrigando-se os fornecedores, em qualquer hipótese, a dar as informações necessárias e adequadas a seu respeito.

Art. $9^{\circ} \mathrm{CDC} \mathrm{O}$ fornecedor de produtos e serviços potencialmente nocivos ou perigosos à saúde ou segurança deverá informar, de maneira ostensiva e adequada, a respeito da sua nocividade ou periculosidade, sem prejuízo da adoção de outras medidas cabíveis em cada caso concreto.
}

Revista de Direito Ambiental e Socioambientalismo | e-ISSN: 2525-9628 | Belém | v. 5 | n. 2 | 
consequências relacionadas com a força ameaçadora da modernização e com a globalização da dúvida.

Há a consternação, pois parte dos registros de 2019 contêm princípios ativos já autorizados para uso, porém sem avaliação da periculosidade toxicológica e dos riscos em suas combinações. Portanto, não se sabe ao certo o impacto proveniente da liberação dessas centenas de produtos ao meio ambiente e à saúde da população. Além do mais, dentre estes, está o glifosato, ainda sob processo de reavaliação no Brasil, sob análise na União Europeia, proibido na França a partir de 2022 e alvo milhares de ações judiciais movidas por fazendeiros norte-americanos que desenvolveram câncer e apresentam laudos periciais médicos comprovando a relação entre a doença e o contato com o glifosato (BOMBARDI, 2017, p.38).

Outro exemplo citado por Larissa Bombardi (2017, p.40), no Atlas Agrotóxico, é o do ingrediente ativo acefato, o qual é o terceiro mais vendido no Brasil, proibido na Europa e anteriormente barrado pelo Relatório Técnico da Anvisa por conta da acentuada neurotoxicidade. Com a nova classificação, produtos proibidos em outros países, permanecem e/ou entram com maior facilidade no país, contabilizando-se 30\% destes em 2019.

Nota-se que o Brasil caminha no sentido contrário dos acordos e tratados internacionais ratificados. O Acordo Regional sobre Acesso à Informação, Participação Pública e Acesso à Justiça em Assuntos Ambientais na América Latina e no Caribe, doravante conhecido por Acordo de Escazú, por ocasião da cidade de celebração em Costa Rica, teve seus primórdios na Conferência das Nações Unidas sobre Desenvolvimento Sustentável (Rio+20), fundamentando-se no Princípio $10^{9}$ da Declaração do Rio sobre Meio Ambiente e Desenvolvimento. Nesse ínterim, Paulo Affonso da Silva (2019, p.15) reforça que o princípio 10 da Declaração Rio/92 “mesmo não tendo a força obrigatória de uma convenção - ratificada e promulgada -, desempenhou o papel de farol condutor das discussões e decisões dos países integrantes do Acordo Regional".

Num momento de crescente incerteza e profundos desequilíbrios econômicos,

\footnotetext{
9 Princípio 10 A melhor maneira de tratar as questões ambientais é assegurar a participação, no nível apropriado, de todos os cidadãos interessados. No nível nacional, cada indivíduo terá acesso adequado às informações relativas ao meio ambiente de que disponham as autoridades públicas, inclusive informações acerca de materiais e atividades perigosas em suas comunidades, bem como a oportunidade de participar dos processos decisórios. Os Estados irão facilitar e estimular a conscientização e a participação popular, colocando as informações à disposição de todos. Será proporcionado o acesso efetivo a mecanismos judiciais e administrativos, inclusive no que se refere à compensação e reparação de danos. (Grifos Nossos).
} 
sociais e ambientais, em que, precisamente, o multilateralismo encontra-se submetido a um intenso escrutínio, os países da América Latina e do Caribe demonstraram o valor da ação regional. [...] Não pode haver crescimento às custas do meio ambiente, e não se pode gerir o meio ambiente ignorando nossos povos e nossas economias. A segurança jurídica e a confiança nas instituições públicas também são cruciais para o desenvolvimento sustentável. O Acordo reconhece essa inter-relação e interdependência, o que converte este primeiro tratado regional da CEPAL num instrumento inestimável para obter a implementação da Agenda 2030 para o Desenvolvimento Sustentável. (ORGANIZAÇÃ̃O DAS NAÇÕES UNIDAS, 2018, p. 07-09).

Logo no início do acordo (art. $2^{\circ}$ ) pontua-se o direito de acesso à informação ambiental, primando pelo direito à participação pública nos processos de tomada de decisão em questões ambientais e os deveres das autoridades e instituições em veiculá-las de forma ampla e transparente. Enfatiza-se a necessidade de comunicação das autoridades competentes sobre as informações relacionadas aos riscos ambientais e possíveis impactos adversos associados que afetem ou possam afetar o meio ambiente e a saúde, podendo, inclusive, serem requeridas sem que o solicitante tenha que justificar o seu pedido (artigo 5.2) ${ }^{10}$.

Conforme se vê, o incentivo ao uso desmedido de agrotóxicos implica em retrocessos, principalmente na transparência e confiança esperada da comunicação entre fornecedor e consumidor, pois as substâncias tóxicas continuam as mesmas com mudança, tão somente, na classificação de sua periculosidade. Michel Prieur enfatiza a necessidade em se proibir a regressão dos direitos até então conquistados, no intuito de não incidir em retrocessos, como disposto no art. $3^{\circ}$, “c", do Acordo de Escazú, primando-se na progressão destes ao se exigir a correta rotulagem dos agrotóxicos alertando quanto aos riscos toxicológicos à saúde humana e ambiental:

Em face dessas ameaças de regressão, os juristas ambientais devem reagir de maneira dura, com fundamento em argumentos jurídicos inquestionáveis. A opinião pública, uma vez alertada, não admitiria retrocessos na proteção ambiental, visto que isso implica ameaça à própria saúde humana (PRIEUR, 2011, p.13).

Em igual sentido, a Convenção de Aarhus (Convenção da Comissão Económica para a Europa das Nações Unidas), ratificada na Dinamarca, dispõe sobre Acesso à Informação, Participação do Público no Processo de Tomada de Decisão e Acesso à Justiça em Matéria de Ambiente, com o objetivo de contribuir e proteger o direito de cada pessoa, das gerações presentes e futuras, a viver em um meio ambiente que permita garantir sua saúde e seu bem-estar.

Reconhece a Convenção que um maior acesso do público à informação sobre

\footnotetext{
${ }^{10}$ Artigo 5. Acesso à Informação Ambiental. [...] 2. O exercício do direito de acesso à informação ambiental compreende: a) solicitar e receber informação das autoridades competentes sem necessidade de mencionar um interesse especial nem justificar as razões pelas quais se solicita;
} 
ambiente e a divulgação desta contribui para uma maior sensibilização da população para as questões ambientais, numa participação mais efectiva do público no processo de tomada de decisão e, finalmente, para um ambiente melhor. Consolida, ainda, três pilares (direito à informação ambiental, a participação do público na tomada de decisões e o acesso à justiça em assuntos ambientais), conforme exposto a seguir:

Em seu primeiro artigo, a Convenção de Aarhus garante, em conformidade com as suas disposições, os direitos de acesso à informação ambiental, a participação do público na tomada de decisões e o acesso à justiça em assuntos ambientais que são conhecidos como os três pilares ou o tripé de Aarhus por serem elementos chaves que tornamrealidade a própria democracia e por constituírem o "Direito Internacional do Meio Ambiente contemporâneo, além de transpor que os limites dos consensos regionais como o meio ambiente deve ser protegido pelos Estados. (NEVES; MOREIRA, 2015, p. 564)

Com o devido enfoque no direito à informação e participação coletiva na tomada de decisões, a Convenção de Aarhus relaciona direitos humanos e a efetivação do Estado Democrático de Direito, pois como salienta Razquin Lizarraga (2005), a informação e a participação pública são "elementos chave no discurso político do presente momento em um contexto geral de 'novo modelo de governo' caracterizado pela transparência, responsabilidade e participação dos cidadãos. E, ainda, conforme ensina Ballesteros-Pinilla (2010, p.27):

\begin{abstract}
A participação cidadã no âmbito da proteção ambiental objetivada pela Convenção de Aarhus é mais intensa devido a duas razões fundamentais: (1) a primeira, referese à participação como um instrumento que garante o funcionamento democrático das sociedades e que introduz maior transparência na gestão dos assuntos públicos que permite fazer um contrapeso dos interesses econômicos que postulam em favor do desenvolvimento descontrolado. Além disso, a participação cidadã é indispensável para determinar o nível de risco relevante, ante o qual devem adotar-se medidas antecipatórias baseadas no Princípio da Precaução.[...]Já a (2) segunda razão fundamental consiste na permissão e a participação de organizações ambientais que atuam como instrumentos de controle estatal, já que um dos contrastes do direito ambiental é que os poderes públicos, a quem o ordenamento jurídico atribuia função de zelar pelo meio ambiente, aparecem com frequência como agressores desse mesmo bem jurídico. Daí porque, a participação da sociedade civil no processo de tomada de decisão, em matéria ambiental, não funciona somente como um "pilar de Aarhus", mas como Princípio, como integrante do corpo iuris dos direitos humanos e como postulado funcional, ou melhor, diretriz que deve orientar os Estados e todos os poderes públicos no seu dever de proteger o meio ambiente.
\end{abstract}

Nesse sentido, com base nas normas internas, internacionais, estudos científicos e dados expostos, a nova reclassificaçao da ANVISA se dá em detrimento aos riscos a saúde coletiva e aos direitos ambientais, e caracteriza um retrocesso normativo, pois a recategorização de agrotóxicos de alta toxidade como de menor toxidade, consubstancia-se 
em verdadeiro mascaramento da comunicação dos riscos à saúde humana e ao meio ambiente ecologicamente equilibrado, em um país pautado na cultura agrícola de agrotóxicos, culminando em verdadeiro retrocesso de direitos adquiridos.

\section{CONSIDERAÇÕES FINAIS}

Diante da ameaça concreta de retrocessos normativos ao direito à informação e à saúde humana, cabe à sociedade brasileira mobilizar-se, por meio de seus diversos atores sociais, de modo a exigir a mudança das diretrizes econômicas de rotulagem e registro de agrotóxicos, bem como, posicionar-se contra a utilização desenfreada de agrotóxicos na agroindústria em território nacional. Os retrocessos normativos no sistema de controle de agrotóxicos atingem de forma direta e imediata os trabalhadores rurais, nem sempre capacitados para o manuseio de pesticidas e expostos de forma excessiva, sem a devida comunicação e informação dos riscos a sua saúde.

Consta-se que na recente delimitação toxicológica dos agrotóxicos pela Anvisa, em 23 de Julho de 2019, a escolha de parâmetros para a reclassificação toxicológica dos pesticidas não privilegiou a informação clara e objetiva ao usuário e consumidor, uma vez que o novo parâmetro utilizado pela Anvisa não privilegia a precaução e a comunicação de riscos, o que resta evidente diante do aumento excessiva da quantidade de produtos autorizados. E, por mais que possa se afirmar que se está aplicando parâmetros semelhantes a regulação internacional, há um evidente déficit de segurança de riscos no território brasileiro, onde há a liberação de agrotóxicos já proibidos no restante do mundo.

Os riscos de contaminação da saúde humana e ambiental pelo uso excessivo, inadequado e abusivo de agrotóxicos pela agroindústria em território brasileiro é uma realidade cotidiana no campo e a comunicação de riscos é um direito fundamental que deve ser priorizado e garantido de forma ampla a todo cidadão usuário e consumidor, e deve privilegiar a prevenção e não contribuir para induzir em erro e facilitar o comércio de um produto de tão alto grau de risco de intoxicação que pode afetar de forma grave e determinante a saúde socioambiental.

\section{REFERÊNCIAS}

ABRASCO. Associação Brasileira de Comércio Orgânico. Dossiê Abrasco 2015: um alerta sobre os impactos dos agrotóxicos na saúde. Disponível em: http://www. 
abrasco.org.br/dossieagrotoxicos/wp-content/uploads/2013/10/DossieAbrasco_2015_ web.pdf. Acesso em: 26 mar. 2019

ALBERGONI, Leide; PELAEZ, Victor. Da Revolução Verde à agrobiotecnologia: ruptura ou continuidade de paradigmas? Revista de Economia, v. 33, n. 1, p.31-53, jan/jun, 2007.

AMARO, Pedro. A política de redução dos riscos dos pesticidas em Portugal. Lisboa: ISA/Press, 2007.

ANVISA, Agência Nacional de Vigilância Sanitária. Programa de Análise de Resíduos de Agrotóxicos em Alimentos (PARA). Relatório de Atividades de 2011 e 2012. Brasília: Agência Nacional de Vigilância Sanitária; 2013.

Regularização de Produtos - Agrotóxicos: registro de produtos. Disponível em: $<$ http://portal.anvisa.gov.br/registros-e-autorizacoes/agrotoxicos/produtos/registro $>$. Acesso em: 11 jun. 2019.

BALLESTEROS-PINILLA, Gabriel. La participaciónen assuntos ambientales y su tutela enel Convenio de Aarhus. Vniversitas. n. 121. Bogotá. 2010.

BECK, Ulrich. Sociedade de risco: rumo a uma outra modernidade. 2. ed. São Paulo: Editora 34, 2011.

Ecological politics in an age of risk. Trad. Amos Weisz. Cambridge: Polity, 1995.

BOMBARDI, Larissa Mies. Geografia do uso de agrotóxicos no Brasil e conexões com a união europeia. São Paulo: FFLCH - USP, 2017.

Questão dos agrotóxicos exige debate qualificado, escreve Larissa Bombardi. Disponível em: https://www.poder360.com.br/opiniao/economia/questao

-dos-agrotoxicos-exige-debate-qualificado-escreve-larissa-bombardi/. Acesso em: 01 set. 2019.

BOSSELMANN, Klaus. O princípio da sustentabilidade: transformando direito e governança. Trad. Phillip Gil França. São Paulo: Revista dos Tribunais, 2015.

BRASIL, Decreto no 4.074 de 04 de Janeiro de 2002. Regulamenta a Lei no 7.802, de 11 de julho de 1989. Diário Oficial da União, 05 de Janeiro de 2002.

Lei $\mathbf{n}^{\mathbf{0}}$ 7.802 de 11 de Julho de 1989. Diário Oficial da União, 12 de Julho de 1989.

. Ministério da Economia. Convênio ICMS no 100/97 CONFAZ. Disponível em:

https://www.confaz.fazenda.gov.br/legislacao/convenios

/1997/CV100_97. Acesso em: 02 set. 2019.

Ministério da Saúde. RDC no 44 de 04 de maio de 2000. Disponível em:

http://www.lex.com.br/doc_1083001_RESOLUCAO_RDC_N_44_DE_10_DE_MAIO_DE_ 2000.aspx. Acesso em: 01 set. 2009.

Ministério do Meio Ambiente. Declaração do Rio sobre Meio Ambiente e

Desenvolvimento. Disponível em: http://www.meioambiente.pr.gov.br/arquivos/File/ agenda21/Declaracao_Rio_Meio_Ambiente_Desenvolvimento.pdf. Acesso em: 01 set. 2009.

CAPRA, Fritjof. As conexões ocultas: Ciência para uma vida sustentável. Trad: Marcelo Brandão Cipolla. 5ª Reimpressão. São Paulo: Cultrix, 2005.

Revista de Direito Ambiental e Socioambientalismo | e-ISSN: 2525-9628 | Belém | v. 5 | n. 2 |

p. 55 - 76 | Jul/Dez. 2019. 
CODONHO, Maria Leonor Paes Cavalcanti Ferreira. Desafios para a concretização da agricultura sustentável no Brasil: uma contribuição do direito para a regulação do uso dos agrotóxicos. Instituto O Direito por um Planeta Verde, 2014.

FRANCO, Tânia; DRUCK, Graça. Padrões de industrialização, riscos e meio ambiente. Ciência \& Saúde Coletiva, v. 3, p. 61-72, 1998.

GOMES, Carla Amado. Risco e modificação do acto autorizativo concretizador de proteç̧ão do ambiente. Coimbra: Coimbra Editora, 2007.

JANSEN, Roberta. Pesquisa indica que não há dose segura de agrotóxico. Disponível em: https://noticias.uol.com.br/meio-ambiente/ultimas-noticias/ag-estado

/2019/08/04/pesquisa-indica-que-nao-ha-dose-segura-deagrotoxico.amp.htm?_twitter_ impression=true. Acesso em: 01 set. 2019.

LOPES, Carla Vanessa Alves; ALBUQUERQUE, Guilherme Souza Cavalcanti de. Agrotóxicos e seus impactos na saúde humana e ambiental: uma revisão sistemática. Saúde em Debate, v. 42, p. 518-534, 2018.

LOPES, Érica Valente. Alimentos transgênicos: direito à informação e responsabilidade civil diante de danos à saúde. Fortaleza: Editora Din.CE, 2013.

MACHADO, Paulo Affonso Leme. Direito à informação e meio ambiente. rev., ampl. e atual. São Paulo: Malheiros, 2018.

, Paulo Affonso Leme. Estudos de direito ambiental 3. São Paulo: Malheiros, 2019.

NEVES, Rafaela Teixeira; MOREIRA, Eliane Cristina Pinto. Os princípios da participação e informação ambientais e a aplicação da Convenção de Aarhus no direito brasileiro. Revista de Direito Ambiental, v. 77, p. 563-588, 2015.

NODARI, Rubens Onofre. Agrotóxicos: a nossa saúde e o meio ambiente em questão: aspectos técnicos, jurídicos e éticos. Risco à saúde dos seres vivos advindo dos agrotóxicos: ênfase nos herbicidas. Florianópolis: FUNJAB, p. 111-146, 2012.

MAPA, Ministério da Agricultura, Pecuária e Abastecimento. Anvisa vai reclassificar defensivos agrícolas que estão no mercado. Disponível em:

http://www.agricultura.gov.br/noticias/anvisa-vai-reclassificar-todos-os-agrotoxicos-queestao-no-mercado. Acesso em: 30 ago. 2019.

ORGANIZAÇÃO DAS NAÇÕES UNIDAS, Cepal. Acordo Regional sobre Acesso à Informação, Participação Pública e Acesso à Justiça em Assuntos Ambientais na América Latina e no Caribe, 2018.

Convenção de Aarhus. Disponível em: https://apambiente.pt/index.php?ref

$=16 \&$ subref $=142 \&$ sub2ref=726\&sub3ref $=727$. Acesso em: 09 nov. 2018.

PADILHA, Norma Sueli. Fundamentos constitucionais do direito ambiental brasileiro.

Rio de Janeiro: Elsevier, 2010.

PINA, Rute. Brasil deixou de arrecadar $\mathbf{R} \$ 2$ bilhões com isenções a agrotóxicos em 2018: Perda tributária com comercialização de venenos agrícolas cresceu $32 \%$ em um ano. Revista Brasil de Fato. 2 abr 2019. Disponível em: https://www.brasildefato

.com.br/2019/04/02/brasil-deixou-de-arrecadar-rdollar-2-bilhoes-com-isencoes-a-agrotoxicos-

Revista de Direito Ambiental e Socioambientalismo | e-ISSN: 2525-9628 | Belém | v. 5 | n. 2 |

p. 55 - 76 | Jul/Dez. 2019. 
em-2018/. Acesso em: 02 set. 2019.

PORTO, Marcelo Firpo de Souza. Entre a prevenção e a precaução: riscos complexos e incertos e as bases de uma nova ciência da sustentabilidade. In: BARCELLOS, Christovam (org). Território, ambiente e saúde. Rio de Janeiro: Editora Fiocruz, p. 143-157, 2008.

PRIEUR, Michel. O Princípio da Proibição de Retrocesso Ambiental. Senado Federal: Comissão de Meio Ambiente, Defesa do Consumidor e Fiscalização e Controle, 2011. Disponível em: <http://www2.senado.leg.br/bdsf/bitstream/handle /id/242559/ 000940398.pdf?sequence=2> Acesso em: 14 abr. 2019.

RANGEL-S, Maria Ligia. Comunicação no controle de risco à saúde e segurança na sociedade contemporânea: uma abordagem interdisciplinar. Ciência \& Saúde Coletiva, v. 12, p. 1375-1385, 2007.

RAZQUIN, José Antonio Lizarraga. EI Convenio de Aarhus. Consecuencias de suratificacíon por España. Revista AJA -Actualidade Jurídica Aranzadi, XV, N 670, Madrid, 2005.

SAMPAIO, Cristiane. Nova classificação de agrotóxicos é "forma de enganar a sociedade", diz pesquisador: Metodologia muda rótulo dos produtos; Greenpeace aponta que sistematização confunde consumidores. Brasil de Fato, 2019. Disponível em: https://www.brasildefato.com.br/2019/07/24/especialistas-criticam-nova-classificacao-deagrotoxicos-da-anvisa/. Acesso em: 30 jul. 2019.

SARLET, Ingo Wolfgang. A eficácia dos direitos fundamentais: uma teoria geral dos direitos fundamentais na perspectiva constitucional. Porto Alegre: Livraria do Advogado, 2018 .

Ingo Wolfgang; FENSTERSEIFER, Tiago. Princípios do direito ambiental. 2. ed. São Paulo: Saraiva Educação SA, 2017.

SHIVA, Vandana. The violence of green revolution: Third world agriculture ecology and politics. 3. ed. USA: Zed books Ltd, 1997.

STIGLITZ, Joseph E. A globalização e seus malefícios. São Paulo: Futura, 2002.

STOPPELLI, Illona Maria de Brito Sá; MAGALHÃES, Cláudio Picanço. Saúde e segurança alimentar: a questão dos agrotóxicos. Ciência \& Saúde Coletiva, v. 10, p. 91-100, 2005.

THRUPP, Lori Ann. Inappropriate incentives for pesticide use: Agricultural credit requirements in developing countries. In: Agriculture and Human Values. Summer Fall, v. 7, n. 3-4, p. 62-69, 1990. 